Table 1. Hypothesized and actual correlations for convergent validity

\begin{tabular}{|c|c|c|c|c|c|}
\hline & \multicolumn{2}{|c|}{ Hypothesized } & \multicolumn{2}{|c|}{ Actual } & \multirow{2}{*}{$\begin{array}{c}\text { Hypotheses } \\
\text { Met }\end{array}$} \\
\hline & Direction & $\mathbf{R}$ & $\mathbf{R}$ & $\begin{array}{c}\mathrm{p}- \\
\text { value }\end{array}$ & \\
\hline \multicolumn{6}{|l|}{ Internal resource } \\
\hline Pain self-efficacy & + & $0.30-0.50$ & 0.48 & 0.000 & Yes \\
\hline \multicolumn{6}{|l|}{ Mental well-being } \\
\hline HADS anxiety & - & $\begin{array}{c}-0.30-- \\
0.50\end{array}$ & -0.37 & 0.000 & Yes \\
\hline HADS depression & - & $\begin{array}{c}-0.30-- \\
0.50\end{array}$ & -0.31 & 0.000 & Yes \\
\hline SF-36 mental health & + & $0.30-0.50$ & 0.30 & 0.000 & Yes \\
\hline \multicolumn{6}{|l|}{ Physical well-being } \\
\hline WOMAC physical function & - & $>-0.30$ & -0.17 & 0.000 & Yes \\
\hline WOMAC pain & - & $>-0.30$ & -0.16 & 0.000 & Yes \\
\hline WOMAC stiffness & - & $>-0.30$ & -0.11 & 0.005 & Yes \\
\hline SF-36 physical functioning & + & $<0.30$ & 0.15 & 0.000 & Yes \\
\hline \multicolumn{6}{|l|}{ Social well-being } \\
\hline $\begin{array}{l}\text { Lubben's social network } \\
\text { score }\end{array}$ & + & $<0.30$ & 0.22 & 0.000 & Yes \\
\hline
\end{tabular}

HADS:Hospital Anxiety \& Depression Scale; SF-36:Short-Form 36; WOMAC:Western Ontario \& McMaster Universities Osteoarthritis Index

Disclosure of Interests: Ka Keat Lim: None declared, Yu Heng Kwan: None declared, Seng Jin Yeo: None declared, William Yeo: None declared, Julian Thumboo: None declared, David Matchar: None declared, Ying Ying Leung Grant/research support from: Abbvie, Novartis, Speakers bureau: Abbvie and Novartis, Speakers bureau: Novartis DOI: 10.1136/annrheumdis-2019-eular.1014

\section{AB1325 HAND FUNCTION IS IMPAIRED IN PATIENTS WITH RHEUMATOID ARTHRITIS, PSORIATIC ARTHRITIS, AND PSORIASIS COMPARED TO HEALTHY CONTROLS}

Anna-Maria Liphardt ${ }^{1}, 2$, Sonja Liehr ${ }^{1}$, Eva Manger ${ }^{1}$, Lisa Bieniek ${ }^{1}$, Arnd Kleyer ${ }^{1}$, David Simon ${ }^{1}$, Koray Tascilar ${ }^{1}$, Michael Sticherling ${ }^{3}$, Jürgen Rech ${ }^{1}$, Georg Schett ${ }^{1}$, Axel Hueber ${ }^{1,4}$. ${ }^{1}$ Friedrich-Alexander-University Erlangen-Nuremberg, University Hospital Erlangen, Internal Medicine 3 - Rheumatology and Immunology, Erlangen, Germany; ${ }^{2}$ German Sport University Cologne (DSHS Köln), Biomechanics and Orthopaedics, Köln, Germany; ${ }^{3}$ Friedrich-Alexander-University Erlangen-Nuremberg, Dermatology, Erlangen, Germany; ${ }^{4}$ Sozialstiftung Bamberg, Rheumatology, Bamberg, Germany

Background: Inflammatory-rheumatic diseases affect hand joints with swelling and pain, leading to joint destruction. Even patients with psoriasis only may suffer subclinical inflammation in the hand joints, leading to changes of bone [1]. Finger joint involvement is different for rheumatoid arthritis (RA), psoriatic arthritis (PsA) and psoriasis (Pso) but hand function in these patients is not well characterized.

Objectives: To quantify and compare grip strength and hand function in patients with RA, PsA and Pso and to relate these outcomes to disease activity.

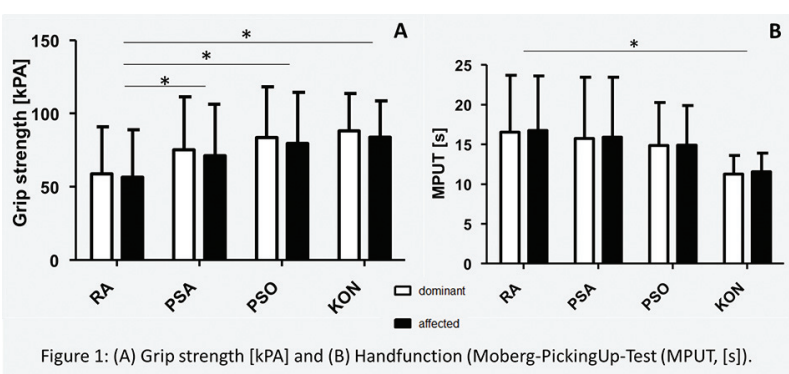

Figure 1

Methods: Patient diagnosed with RA (ACR/EULAR 2010), PsA (Caspar) and Pso and 54 healthy individuals were included in the study after written informed consent. Maximal isometric grip strength (kPA) was measured with a hand dynamometer (Lafayette Instrument, Lafayette, IN, USA) as the highest value out of three measurements. Hand function was determined by way of the Moberg Picking-Up Test (MPUT) and the fastest (s) of two measurements was used. Disease activity was calculated as DAS28_ESR and TJC/SJC 78/76 was recorded. One-way Analysis of Variance (ANOVA), factorial ANOVA and Games-Howell post-hoc testing was performed $(p<0.05)$

Results: 101 RA (63 f; $38 \mathrm{~m}$; age: $59.1 \pm 13.2 \mathrm{yrs}$ ), 92 PsA (48 f, $44 \mathrm{~m}$; age $54.8 \pm 11.6 \mathrm{yrs})$ and 51 Pso patients (19 f, $32 \mathrm{~m}$; age 47.3 \pm 14.1 yrs), as well as 54 healthy control subjects ( $30 \mathrm{f}, 24 \mathrm{~m}$; age $54.6 \pm 16.5$ yrs) participated in the study. Disease duration (yrs) was not different between groups (RA: $11.03 \pm 10.1$, PsA: $9.1 \pm 9.75$, Pso: $12.5 \pm 11.7$; $\mathrm{p}=0.156$ ) but Pso patients in our cohort were younger compared to RA and PsA patients. Mean DAS28_ESR was < 3.2 for all patient groups with control subjects (DAS28 $1.6 \pm 0.7$ ) having lower scores compared to all patient groups and Pso patients presenting with lower DAS28 (2.3 $\pm 1.3)$ compared to RA $(3.0 \pm 1.3)$ and PsA (2.9 \pm 1.3$)$. While TJC was higher for all patients compared to controls (RA: $5.2 \pm 6.8$, PsA: $5.9 \pm 8.1$ Pso: $3.2 \pm 6.4$; CON: $0.5 \pm 1.4 ; p=0.00$ ), SJC was higher for RA and PsA compared to Pso and CON (RA: $0.7 \pm 1.0$, PsA: $0.9 \pm 2.2$ Pso: $0.1 \pm 0.3$; CON: $0.5 \pm 1.4 ; p=0.000)$. Grip strength of the dominant and/or affected hand of RA patients was lower compared to PsA, Pso and CON (Figure 1A). In contrast to this, hand function of the same hand in all tested patient groups was reduced compared to CON (Figure 1B). The results for grip strength and hand function were not different for the dominant and the affected hand and are independent of age differences between groups.

Conclusion: Overall, RA patients showed significantly lower grip strength compared to PsA and Pso patients as well as to the control group, whereas all three patient groups performed worse in the MPUT compared to the control cohort. This suggests that grip strength may be preserved longer than hand function in patients with inflammatory rheumatic disease. Further, it was surprizing that hand function was reduced in Pso patients without arthritic correlate compared to healthy subjects. This suggests that hand function may provide a potential parameter for discriminating Pso patients at risk for subclinical joint involvement.

This study was funded by research support from Novartis Pharma, $\mathrm{GmbH}$.

\section{REFERENCES}

[1] Faustini F, Simon D, et al. 2016, Ann Rheum Dis 75: 2068-2074.

Disclosure of Interests: Anna-Maria Liphardt Grant/research support from Novartis Pharma GmbH, Sonja Liehr: None declared, Eva Manger: None declared, Lisa Bieniek: None declared, Arnd Kleyer Grant/research support from: Lilly, Consultant for: Lilly, Speakers bureau: Abbvie, David Simon Grant/research support from: Novartis, Consultant for: Lilly, Speakers bureau: Janssen, Koray Tascilar: None declared, Michael Sticherling: None declared, Jürgen Rech Grant/research support from: Bristol-Myers Squibb and Celgene (greater than $\$ 10,000$ ), Consultant for: Bristol-Myers Squibb, Celgene, Chugai, GlaxoSmithKline, Janssen, Eli Lilly, Novartis, Roche, Sanofi Aventis, and UCB (in total more than $\$ 10,000$ ), Speakers bureau: Bristol-Myers Squibb, Celgene, Chugai, GlaxoSmithKline, Janssen, Eli Lilly, Novartis, Roche, Sanofi Aventis, and UCB (in total more than $\$ 10,000$ ), Georg Schett: None declared, Axel Hueber Grant/research support from: Novartis, Pfizer, Consultant for: Lilly, Speakers bureau: Lilly, Novartis, Janssen, Abbvie

DOI: 10.1136/annrheumdis-2019-eular.4733

\section{AB1326 INCREASED FIBRINOGEN TO ALBUMIN RATIO IN ANKYLOSING SPONDYLITIS: CORRELATION WITH DISEASE ACTIVITY}

Meng Liu, Yukai Huang, Zhengping Huang, Qidang Huang, Xin Guo, Yunqing Wang, Wengming Deng, Zhi-Xiang Huang, LI Tian-Wang. Guangdong Second Provincial General Hospital, Department of Rheumatology and Immunology, Guangzhou, China

Background: Fibrinogen to albumin ratio (FAR) has emerged as a new effective biomarker which can reflect the severity of chronic inflammation. However, none of study has focused on the role of FAR in ankylosing spondylitis (AS).

Objectives: The study aimed to investigate the association between FAR and the disease activity of AS.

Methods: The retrospective study included 117 AS patients and 165 ageand gender-matched healthy controls. AS patients were divided into remission group (Bath Ankylosing Spondylitis Disease Activity Index 